\title{
A REFORMA DO ENSINO MÉDIO COMO SUBMISSÃO AOS ARRANJOS PRODUTIVOS LOCAIS: UMA PERSPECTIVA A PARTIR DO IFSP DE SÃO ROQUE
}

\author{
Caíque Diogo de Oliveira ${ }^{1}$ \\ ${ }^{1}$ Graduado em Engenharia de Produção pela Universidade de Sorocaba. Mestrando em Educação pela Universidade Federal de São Carlos - UFSCar, \\ Sorocaba, SP. E-mail: caique.diogo@outlook.com.br
}

\section{RESUMO}

Atualmente, com a reforma do Ensino Médio, verificamos mais uma vez o interesse do Estado na descentralização das responsabilidades do ensino e da educação escolar aumentando a autonomia da esfera local. Portanto, este trabalho pretende verificar as relações que envolvem a economia local no município de São Roque no Estado de São Paulo e a constituição dos cursos de nível médio do Instituto Federal de Educação, Ciência e Tecnologia campus São Roque no sentido de compreender como a educação para o trabalho se articula com os agentes econômicos locais. Para realizar a investigação o estudo assumiu um caráter exploratório com o uso da análise documental. Os resultados apontaram para a ocorrência de um arranjo produtivo local com ênfase na produção de vitivinicultura e uma articulação entre as opções de formação em cursos de nível médio Integrado e as premissas de fortalecimento da aglomeração produtiva regional.

Palavras - chave: Reforma do Ensino Médio; Educação Profissional; Educação e trabalho; Arranjos produtivos locais; Economia local.

\section{THE REFORM OF HIGH SCHOOL AS A SUBMISSION TO CLUSTERS: A PERSPECTIVE FROM THE IFSP OF SÃO ROQUE}

\begin{abstract}
Today, with the Reform of High School, we once again see the interest of the State in decentralization of the responsibilities of teaching and school education, increasing the autonomy of the local sphere. Therefore, this work intends to verify relationships that involve the local economy in the city of São Roque in the State of São Paulo and the constitution of middle level courses of the Federal Institute of Education, Science and Technology campus São Roque in order to understand how education for the work is articulated with the local economic agents. To carry out the investigation the study assumed an exploratory character with the use of documentary analysis. The results pointed to the occurrence of a cluster with emphasis on the wine production and an articulation between the occurrence of integrated middle level courses and the premises of strengthening the cluster.
\end{abstract}

Keywords: Reform of high school; Professional Education; Education and work; clusters; Local economy.

\section{INTRODUÇÃO}

O nível educacional que hoje conhecemos como Ensino Médio, nasce da reformulação da educação brasileira posterior ao período da ditadura militar no Brasil e está amparada tanto pela constituinte de 1988 quanto a Lei de Diretrizes e Bases da Educação - LDB - Lei 9.394 de 1996, sendo a última etapa da educação básica com duração de três anos e assegurada como dever pelo Estado.
A partir da LDB de 1996 o Ensino Médio passou a fazer parte da educação básica no Brasil, abrindo aos jovens a possibilidade de acesso a um nível de escolaridade mais elevado, criandose uma nova e expressiva demanda por matrículas a essa etapa. Com base nos dados do INEP (2015) e no estudo de Sposito e Souza (2014) por meio do qual percebemos que o período que vai dos anos de 1991 a 2013 delineiam dois momentos distintos no Ensino Médio brasileiro. $O$ primeiro tem como marco o 
momento compreendido entre 1991 e 2004, quando foi possível registrar um incremento significativo no número de alunos, saltando de aproximadamente 3,8 milhões de alunos em 1991 para 9,2 milhões em 2004. O segundo momento entre 2004 e 2014 passa a registrar uma queda no número de alunos, passando de aproximadamente 9,2 milhões de alunos para em 2013 registrar 8,3 milhões de alunos no Ensino Médio. Já os números do INEP (2015) sobre a Educação Profissional disponíveis no mesmo censo educacional de 2013 apontam para uma recente expansão da modalidade. Considerando as matrículas da Educação Profissional concomitante, subsequente e integradas ao Ensino Médio, o crescimento foi de 5,8\%, alcançando o contingente de 1,44 milhão de alunos atendidos em 2013. Cabe destaque para a expansão das redes federal e privada, que aumentaram respectivamente $8,4 \%$ e $9,3 \%$ de 2012 para 2013. No período 2007-2013, a rede federal mais que dobrou a oferta de matrícula de Educação Profissional, com um crescimento de $108 \%$. Consequentemente, a expansão do Ensino Médio foi incorporada aos requisitos do mercado de trabalho, progressivamente a formação de nível médio vem sendo cada vez mais necessária para a inserção dos sujeitos na vida produtiva.

O ensino médio brasileiro sempre se constituiu como uma etapa sem uma finalidade definida. Enquanto o ensino fundamental é visto socialmente como responsável por proporcionar aos estudantes conhecimentos básicos de caráter mais geral, e o ensino superior provedor de bases teóricas propicias ao exercício cidadão e profissional, enquanto o Ensino Médio não possui uma identidade definida, se assemelhando ora com o ensino fundamental, ora com o ensino superior.

O Ensino Médio se encontra sob uma disputa de interesses políticos que segundo Ferreti e Silva (2017, p.400):

Tal disputa é histórica em nosso país, ganhando conotações diferenciadas conforme o contexto social e político em que ocorreu. No entanto, merece destaque o fato de que, desde a década de 1970, ela vem sendo marcada na definição das políticas nacionais que dizem respeito ao ensino médio, pela insistência na sua vinculação aos interesses da economia capitalista, atribuindo a essa etapa da formação de jovens um caráter fortemente instrumental, mais do que de formação humana em sentido amplo.

Portanto a Lei no 13.415 , de 16 de fevereiro de 2017 não constitui uma novidade, mas apenas uma atualização da histórica disputa pela finalidade do Ensino Médio brasileiro.

Apesar da semelhança em relação à preocupação com a profissionalização dos alunos do ensino médio, vale ressaltar que a rede federal e a rede estadual detêm diferenças com relação à infraestrutura do sistema educacional e principalmente na relação investimento por aluno ou investimento por docente.

Embora a Base Nacional Curricular Comum - BNCC - não tenha sido lançada até o fim de 2017 e, consequentemente, não haver consenso sobre a organização curricular, Neto (2017) propõe um esboço de como a reforma do Ensino Médio afeta a educação tecnológica da rede federal de educação. $O$ autor enfatiza como a mudança na carga horária da organização curricular irá transformar o segundo e o terceiro ano do curso de nível médio integrado, uma vez que o autor parte do pressuposto de que os Institutos Federais devem optar pelo itinerário formativo da Educação Profissional e Tecnológica, os cursos serão compostos somente por disciplinas de português, matemática e as demais do itinerário formativo da Educação Profissional, de maneira a excluir disciplinas das ciências humanas e das ciências da natureza.

A problemática que estamos considerando aqui é que diante da promessa da reforma de oferecer maior autonomia para as redes de ensino locais, pode-se abrir a possibilidade de proporcionar um Ensino Profissionalizante que atenda estritamente as necessidades e os interesses dos agentes econômicos locais. Para compreender essa articulação iremos discutir como isso ocorre no IFSP campus de São Roque no interior paulista. Os dados que fundamentam os argumentos presentes neste artigo foram obtidos a partir dos resultados e constatações presentes no estudo "arranjos produtivos no segundo-setor no município de Sorocaba e região e as políticas 
públicas de ensino médio" 2, desenvolvido no programa de iniciação cientifica da Universidade de Sorocaba (OLIVEIRA, 2015), cuja produção ocorreu como parte do projeto de pesquisa "Institutos Federais de educação profissional, ciência e tecnologia: um "novo" cenário da educação profissional na região de Sorocaba" ${ }^{3}$ coordenado pelo Prof.o Dr. Jefferson Carriello do Carmo.

A delimitação temporal da pesquisa compreende o fim dos anos 1990 a 2016. Entendemos haver mudanças na economia mundial, brasileira e local. Momento marcado por uma restruturação na produção brasileira devido à liberalização comercial iniciada a partir dos anos de 1990, assim como a implantação de estratégias para o fortalecimento do setor industrial que buscava maior competitividade e uma posição de destaque no cenário internacional. No campo educacional, neste período, foram executadas políticas públicas no âmbito da educação que descentralizam as responsabilidades de manutenção do ensino e da escola, junto ao conflito de interesses entre o público/privado, as organizações não governamentais, o Estado e a comunidade.

Este trabalho pretende verificar as relações que envolvem a economia local no município de São Roque no Estado de São Paulo e a constituição dos cursos de nível médio integrado ao ensino técnico do Instituto Federal de Educação, Ciência e Tecnologia - IFSP campus São Roque no sentido de compreender como a educação para o trabalho se articula com os agentes econômicos locais. De modo a investigar os sentidos assumidos pelo Ensino Médio Integrado ao Ensino Profissionalizante, no contexto das novas formas de produção e os desafios a serem enfrentados na reforma do Ensino Médio em voga desde o fim de 2016.

\footnotetext{
${ }^{2}$ Esta pesquisa está inserida na linha de pesquisa: História e historiografia: políticas e práticas escolares da educação do Programa de Mestrado e Doutorado em Educação. Sendo fortalecido junto ao Grupo de Estudos "Instituição Escolar: História, Escola, Trabalho e Políticas de Educação Profissional" e por meio do Prof. Jefferson, evidenciaram a necessidade de se conhecer a articulação entre o empresariado local e as políticas de educação profissional na Região Metropolitana de Sorocaba.

${ }^{3}$ Este texto faz parte da pesquisa "Institutos Federais de educação profissional, ciência e tecnologia: um "novo" cenário da educação profissional na região de Sorocaba", que está sendo desenvolvida no programa de Mestrado e Doutorado em Educação na Universidade de Sorocaba - UNISO e financiada pelo CNPq (Edital $\mathrm{MCTI} / \mathrm{CNPQ} / \mathrm{MEC} / \mathrm{CAPES} \mathrm{N}^{\circ}$ 22/2014).
}

\section{METODOLOGIA}

A ênfase deste trabalho é não se centrar apenas nos fenômenos que ocorrem dentro da instituição escolar, nos amparamos em Sanfelice (2007) quando destaca a necessidade de ampliar o processo investigativo de pesquisa para além dos muros da instituição escolar, na expectativa de compreender melhor sua identidade. Sanfelice sugere ainda que a investigação através do entorno da instituição escolar pode ser uma caminhada para uma dimensão cada vez mais macro.

Para a organização dos dados iniciais necessários para a descrição do contexto econômico-social onde o curso se insere recorremos à coleta de dados referentes ao ensino de nível médio e a instalação e operação do IFSP no município de São Roque. Utilizamos a documentação oficial e dados quantitativos de bancos estatísticos do Ministério da Educação MEC, Fundação Sistema Estadual de Análise de Dados - SEADE e Instituto Brasileiro de Geografia e Estatística - IBGE.

Um dos documentos utilizados na análise é o Plano de Desenvolvimento Institucional - PDI - para os Institutos Federais de Ensino no Estado de São Paulo 2014-2018. O documento oferece informações, por meio das quais identificamos uma relação entre a ocorrência das APL das empresas do segundo setor na Região de Sorocaba e a oferta de cursos nos institutos locais. Já as fontes secundárias foram os textos e publicações de autores que possuem pesquisas relacionadas às políticas educacionais, à formação profissional e tecnológica, e as demais mediações que acercam o mundo do trabalho e a educação.

\section{Arranjos produtivos locais em um contexto de divisão internacional do trabalho}

A crise de lucratividade do capital ocorrida nos anos de 1960 e 1970, agravada pela crise do petróleo, colocou os detentores dos meios de produção diante da necessidade de uma mudança para a retomada no crescimento das margens de lucratividade (DUMÉNIL; LÉVY, 2014). O modelo de produção baseado no binômio taylorismo-fordismo, cuja aplicação possibilitou ganhos crescentes de escala de produção no início do século XX com a padronização das atividades de trabalho e a consolidação da linha de produção no ambiente fabril, demonstrava cada vez mais suas fragilidades em momentos de variação da 
demanda de consumo, ou na customização da própria linha, frente às diversas possibilidades geradas pelo avanço tecnológico promovido pela microeletrônica. A "saída" para a crise foi encontrada nos modelos de produção japoneses baseados na redução dos estoques de mercadorias, células híbridas de produção com alta customização de sua organização e uma equipe de trabalho formada por operários polivalentes, ou seja, iniciou-se um modelo que flexibiliza diversos espaços que antes eram padronizados.

Além do modelo de produção, a superação da crise dos anos de 1970 encontrou amparo no campo político (DARDOT; LAVAL, 2016). A desilusão da burguesia com o keyneseanismo trouxe à tona, de volta à pauta política, premissas do pensamento liberal. De modo a dar início a uma liberalização econômica dos mercados globais e a desregulamentação das leis trabalhistas. Algumas vertentes teóricas olham para esse movimento histórico e o consideram como um processo, chamando-o de globalização ou mundialização do capital (CHESNAIS, 1996).

Essas pautas de liberalização comercial iniciaram-se no Brasil no governo de Fernando Collor de Mello e, posteriormente, Itamar Franco como medidas de contensão de inflação e da dita baixa produtividade da indústria nacional. Já no governo de Fernando Henrique Cardoso essas pautas ainda estavam presentes, sob o discurso da "modernização brasileira". A entrada de capital e bens do estrangeiro passou a ocupar lugar comum no produto interno bruto brasileiro.

No alvorecer do século XXI, enquanto a classe burguesa encontrava na acumulação flexível e nas políticas de cunho neoliberal as bases para expansão de lucratividade, os trabalhadores diante de uma nova configuração do mercado de trabalho, e os críticos que optavam por uma perspectiva materialista do que estava acontecendo, observavam a acentuação de uma divisão internacional do trabalho, uma financeirização das riquezas, empresas multinacionais monopolizando/oligopolizando a produção e o consumo de bens (ANTUNES, 2009; HARVEY, 2012; POCHMANN, 2012), e a figura do trabalhador se modificando no imaginário idealista, o trabalhador fabril passa a ser substituído agora por alguém que executa um trabalho imaterial dotado de artefatos tecnológicos.
Essa atual divisão internacional do trabalho acirrou uma velha contradição do capital: o impasse entre produção interna e produção externa de um país. Para países que se encontram na periferia dos grandes centros de desenvolvimento tecnológico surge a necessidade do consumo de bens com maior valor agregado, assim, quando esses países optam por limitar a sua economia a importação de bens, acabam por desvalorizar a produção interna, de modo a diminuir seus postos e aumentar os fluxos de capitais em direção aos grandes centros (POCHMANN, 2010, 2012).

Durante o período compreendido entre 2002-2016, o Brasil teve a presidência governada pelo partido dos trabalhadores que se deparou com essa contradição. Considerando que, não há "neutralidade" nas ações diante das contradições, iremos considerar o conceito de arranjos produtivos locais ${ }^{4}$ - APL - como parte dessa contradição e estratégia possível por parte da esfera pública ${ }^{5}$ nesse período.

Historicamente, as aglomerações produtivas têm sua gênese nas observações do economista britânico Alfred Marshall sobre os aglomerados industriais ingleses no século XIX (GARCIA, 2006). Em síntese, pode-se afirmar que APL é uma "concentração setorial e geográfica de empresas." (AMATO NETO, 2008, p.53). Ou seja, empresas de um mesmo segmento, que consomem matérias-primas ou desenvolvem produtos semelhantes e se encontram em uma mesma localidade - municipal ou intermunicipal, de modo que cooperam e competem ao mesmo tempo. Além do mais, os APL podem ser compostos por empresas de variados tamanhos, estruturas e segmentos, variando desde o processo de trabalho artesanal até organizações com alta divisão no processo de trabalho (SACOMANO NETO; PULILLO, 2012).

Outra consequência posta aos APL é a especialização dos trabalhadores locais. Uma vez que o trabalhador interage com a produção de determinada mercadoria de determinado segmento, ele passa a ser visto como conhecedor

\footnotetext{
${ }^{4}$ Arranjos produtivos locais também são conhecidos como clusters pela literatura internacional.

${ }^{5}$ De certa forma, segundo Singer (2016) a derrocada do governo Dilma Housseff encontra a sua gênese na noite de 30 de abril de 2012, quando a presidente dedicou o pronunciamento relativo ao Primeiro de Maio a atacar os bancos, e por meio de decisões monetárias pressionou as instituições privadas a reduzirem seus próprios lucros. Em contrapartida, a "nova matriz" econômica propiciava financiamentos à burguesia nacional via BNDES com fins a estabelecer um crescimento sustentado por caminhos desenvolvimentistas ou neodesenvolvimentistas.
} 
desse produto/segmento. A partir do momento que ocorre a concentração de empresas de um mesmo setor, os trabalhadores passam a ser intercambiáveis nos processos de produção, ficando na eminência da precarização de suas condições laborativas.

A especialização de trabalhadores, assim como a formação destes especialistas, encontra base na teoria do capital humano cuja base está na forma como a relação entre educação e trabalho se submete ao modo de produção do capital. Nela transcorrem que investimentos crescentes em educação e qualificação de trabalhadores causam resultados crescentes no valor econômico regional/nacional. Segundo Frigotto (2010) essa teoria foi aceita nos países emergentes que a adotaram - e continuam a adotar (MOTTA; FRIGOTTO, 2017) - para criar e implementar políticas públicas em educação.

Ao considerar a necessidade de especialização dos trabalhadores na atual organização da educação profissional, observamos o papel exercido por dois agentes econômicos na articulação entre educação e os APL. O primeiro é a iniciativa privada e a execução de seus interesses via a construção de sua ideologia na realidade concreta, levando o trabalhador a pensar que recebe o que é justo por seu trabalho, ao mesmo tempo em que se apoia na modernidade burguesa para paulatinamente responsabilizar os sujeitos por sua condição material, fazendo uso do discurso da qualificação profissional para justificar as decisões dos gestores do capital. E o segundo é o Estado que por meio de suas políticas de educação profissional, reforça as premissas de qualificação profissional esperada pelas empresas.

Uma vez que o mercado de trabalho brasileiro se encontra modificado pela reestruturação produtiva ocorrida entre as décadas de 1980 e 1990 passa a excluir os mais jovens dos empregos melhor remunerados, também retarda a entrada dessas juventudes no mercado de trabalho (GUIMARÃES, 2009) e o Ensino Médio passa a ser visto como mais um pré-requisito $^{6}$ necessário para a inserção no mundo do trabalho. Com o Ensino Médio sendo

\footnotetext{
${ }^{6}$ Segundo Krawczyk (2011) a inclusão do Ensino Médio no âmbito da educação básica e o seu caráter progressivamente obrigatório promovido pela emenda constitucional no 59/2009, amplia a obrigatoriedade escolar para a faixa dos 6 aos 17 anos de idade, demonstrando como as políticas educacionais podem refletem como a atual importância do Ensino Médio.
}

considerado uma passagem obrigatória, políticas de profissionalização na educação transitam com maior frequência nas pautas do Estado brasileiro.

Portanto, direcionaremos um olhar para o Ensino Médio Integrado dos IFSP - campus de São Roque - com a concepção de que ele se encontra em um campo de disputas políticas dotadas de interesses hegemônicos e contra hegemônicos.

\section{Notas sobre o município de São Roque}

As origens do município de São Roque são marcadas pelo trabalho escravo de nativos brasileiros e africanos na produção de trigo e uvas nas fazendas. A construção das primeiras fazendas ocorreu em 1657 por filhos de bandeirantes que também construíram uma capela - onde hoje é considerado o centro da cidade - em devoção ao santo protetor contra pestes. Em 1864, foi elevada à condição de município, e inicia-se um período de chegada de imigrantes europeus que veem nas colinas serranas, no clima e no solo ambiente propício para agricultura, em especial, as parreiras e vinícolas. Com a expansão das atividades das vinícolas, foi realizada em 1942 a primeira Festa do Vinho, foi o primeiro grande evento do Brasil vinculado à produção e comercialização da bebida ${ }^{7}$.

Dados extraídos do IBGE (2017) mostram que a população estimada no município de São Roque para 2017 é de 88.473 habitantes, sendo que $75,97 \%$ são residentes em área urbana. $A$ cidade está localizada a aproximadamente $60 \mathrm{~km}$ da capital paulista, situada entre os municípios de Mairinque, Itu, Araçariguama, Itapevi, Vargem Grande Paulista e Ibiúna.

Embora a emancipação de Araçariguama em 1992 tenha promovido mudanças na economia são-roquense, isso porquê em Araçariguama está localizado um distrito industrial responsável pela geração de empregos e riquezas. Atualmente, São Roque é uma cidade de economia diversificada com atividades no segmento industrial, comercial e na área de serviços. Na segunda metade do século $X X$ as empresas nacionais e multinacionais do setor alimentício e da borracha se instalaram na cidade, diminuindo o impacto das videiras no município. Serviços é o setor que gera o maior

\footnotetext{
${ }^{7}$ Dados do Guia de São Roque em SÃO ROQUE. Estância turística há 351 anos ou a 18 anos?. 2008. Disponível em: <https://www.guiasaoroque.com.br/noticias/estancia-turistica-ha351-anos-ou-ha-18-anos-293 > Acesso em jan de 2018
} 
número de empregos no município com $44 \%$ do total de postos de trabalho, seguido da indústria de transformação com $26 \%$, já o comércio é responsável por $22 \%$ construção civil possui $4 \%$ e a agricultura, pecuária e aquicultura $3 \%$ dos empregos municipais (SEADE, 2015).

Em 1990 São Roque foi elevado à condição de Estância Turística devido ao seu legado histórico e cultural, e também à sua área natural com cerca de $40 \%$ do território do município coberto por Mata Atlântica. Historicamente, o cultivo de uva e as vinícolas fizeram a cidade ser conhecida como a famosa "Terra do vinho".

É com a produção de vinhos que se consolidou no município o cluster registrado no Observatório Nacional de APL (2015) e na Rede Paulista de Arranjos Produtivos Locais (2009) ${ }^{8}$, esse arranjo produtivo de vitivinicultura se agrupa em um espaço denominado "Estrada do vinho", onde além das vinícolas engarrafarem e/ou produzirem vinho, elas também abrem restaurantes e adegas para os visitantes realizarem degustações dos produtos.

A "Estrada do vinho" é considerada um APL por possuir diversos espaços que se concentram um mesmo segmento econômico, assim como utilizam matérias primas semelhantes e, ao mesmo tempo, que precisam competir para o desenvolvimento do melhor vinho precisam cooperar para que esse espaço seja reconhecido e possa atrair o maior número de visitantes.

\section{Ensino médio integrado: o caso do IFSP de São Roque}

A educação para o trabalho também está prevista na constituição de 1988, ela também é conhecida como Ensino Profissionalizante ou

\footnotetext{
${ }^{8}$ A Rede Estadual Paulista é fruto do Decreto № 54.654, DE 7 DE AGOSTO DE 2009 que institui o Programa Estadual de Fomento aos Arranjos Produtivos Locais Artigo $1^{\circ}$ - Fica instituído o Programa Estadual de Fomento aos Arranjos Produtivos Locais com o objetivo de estimular e apoiar:

I - a descentralização do desenvolvimento produtivo, de forma a contribuir para o fortalecimento da economia local e regional;

II - o desenvolvimento das cadeias produtivas paulistas;

III - o aumento da competitividade das micro, pequenas e médias empresas;

IV - o empreendedorismo, baseado na interação e cooperação;

V - a cooperação entre o setor produtivo, entidades de classe e de apoio empresarial, órgãos da Administração Pública, universidades, institutos de pesquisa, desenvolvimento e inovação e centros de educação tecnológica, com vistas ao estabelecimento de estratégias e investimentos conjuntos, ao compartilhamento de infraestruturas, à qualificação da mão-de-obra e outras medidas que levem à melhoria da qualidade dos produtos e processos produtivos, à redução dos custos e à geração de economia de escala.
}

Ensino Técnico, possui espaço na educação de nível médio, com a sansão da Lei 2.208/97 ocorreu uma desarticulação do Ensino Profissional com o ensino propedêutico, o Ensino Profissional passou a ser oferecido à parte do ensino propedêutico podendo ser realizado concomitantemente ao ensino propedêutico ou subsequente ao mesmo. Segundo Ferreti e Silva (2017) esse modelo passou por recusas iniciais e adesões posteriores por parte das escolas técnicas, por força das ações do Ministério da Educação e Cultura e o cenário político nacional e internacional, a separação entre educação propedêutica e educação profissional reforçou a inviabilização de um projeto de educação politécnica.

Com a Lei 5.154 de 23 de julho de 2004, o Ensino Médio passou a poder ofertar Educação Profissional de maneira integrada ao ensino propedêutico e o Ensino Médio Integrado encontrou embasamento legal para vigorar como modalidade nas instituições de ensino, os trabalhos começaram a ser realizados sobre a implantação da modalidade nas escolas técnicas que aderiram ao projeto de "Brasil profissionalizado" proposto pelo governo federal para a ampliação do Ensino Médio Integrado ao Ensino Profissionalizante.

Após a lei 11.892/2008 que aprova a criação dos Institutos Federais de Educação, Ciência e Tecnologia em todos os estados brasileiros com intensos investimentos na criação de cursos de Ensino Médio integrado 9 . O IFSP campus de São Roque foi autorizado pela Portaria Ministerial no. 710, de 09/06/2008. A partir da publicação dessa mesma lei, ficou estabelecido que uma das finalidades dos Institutos Federais é o estímulo e a realização da pesquisa aplicada, visando o desenvolvimento científico e tecnológico, com o objetivo de estender seus benefícios à comunidade.

$$
\text { Ao investigarmos o Plano de }
$$
Desenvolvimento Institucional para os IFSP, referente ao período de 2014-2018 é possível observar entre os objetivos orientadores da pesquisa e desenvolvimento tecnológico dos IFSP's a seguinte referência: "Desenvolvimento de pesquisas para o atendimento de demandas sociais, do mundo do trabalho e da produção, com impactos nos arranjos produtivos locais e contribuição para o desenvolvimento local,

\footnotetext{
9 Na região metropolitana de Sorocaba, há 5 campi do IFSP: Sorocaba, Salto, Boituva, Itapetininga e São Roque.
} 
regional e nacional" (PDI, 2014, p.176, grifo nosso).

No IFSP de São Roque, verifica-se a ocorrência de cursos de nível médio integrado e concomitante/subsequente, superior tecnológico e cursos de pós-graduação. Nosso estudo centrou-se no Ensino Médio Integrado ao Ensino Profissionalizante, oferecidos em três cursos diferentes: administração, alimentos e meio ambiente.

Inicialmente, foi oferecido no IFSP campus de São Roque o curso de nível médio integrado ao técnico em agroindústria. Esse curso apresentou "baixa procura e grande evasão" (BRASIL, 2016b, p. 14), sendo posteriormente substituído pelo curso de mesma modalidade em produção alimentícia que se justifica na formação profissional para a atuação no setor de alimentos de consumo imediato em restaurantes e para o acompanhamento da produção de vinhos, queijos e afins. Segundo dados do SEADE (2015) o comércio é responsável por $22 \%$, e a indústria de transformação $26 \%$ do total de empregos em São Roque, contudo, essa importância da indústria e comércio na economia do município encontra espaço no APL em vitivinicultura organizada na cidade, visto que a "Estrada do vinho" é um espaço de comercialização e produção de vinhos, de modo a demandar profissionais para gerir o comércio e acompanhar a produção de vinhos. Os cursos de administração e meio ambiente aparecem como qualificação que permitem ao egresso se inserir nesta aglomeração local, trazer consigo e reproduzir um mainstream dessa cultura local.

No projeto pedagógico do curso de alimentos, encontramos a seguinte afirmação no item justificativa e demanda de mercado:

Sendo assim, o Campus
São Roque pretende
contribuir para inserção
dos municípios da região
de São Roque nesse
programa,
proporcionando
qualificação profissional,
apoio tecnológico,
promoção do
empreendedorismo e
auxílio a micro, pequenos
e médios empresários,
além de programas de
qualidade ambiental,
através da formação de
força de trabalho direta.

Em 2013 foi implantado no campus São Roque o curso de Tecnologia em Vitivinicultura e Enologia, objetivando consolidar o Instituto Federal de São Paulo na região de São Roque, e pretende-se através do mesmo promover interação com o Curso Técnico em Alimentos Integrado ao Ensino Médio em várias atividades correlatas, numa tentativa de estimular estudantes egressos a atuar na área de produção de alimentos e serviços da alimentação, visando ofertar localmente produtos para compor o leque de opções de consumo ofertado aos frequentadores das atrações turísticas de São Roque (BRASIL, 2016b, p. 14 , grifo nosso).

Assim, verifica-se a articulação do curso com os interesses da economia local, estabelecendo como premissa a formação da força de trabalho direta e indireta.

\section{CONSIDERAÇÕES FINAIS}

Fundamentado pelo método de olhar a escola e a educação escolar para além do cotidiano da sala de aula, constatamos a relação que se estabelece entre o arranjo produtivo local de viticultura do município de São Roque e sua articulação com o Ensino Médio Integrado. De modo que as premissas presentes na literatura sobre os APL quando descrevem uma especialização de profissionais encontra amparo nos interesses dos cursos do IFSP estudado.

De modo geral, visto que a reforma do Ensino Médio em voga desde 2016 possui em suas bases dar maior autonomia regional para a organização dos cursos, assim como faz referências à profissionalização dos educandos como forma de mantê-los nas instituições escolares - diminuindo a evasão escolar-, esperamos com esse artigo suscitar questões sobre os caminhos possíveis da reforma do Ensino Médio, considerando a forma como os cursos do Ensino Médio Integrado ao Ensino Profissional no IFSP campus de São Roque se 
articula com a "estrada do vinho" e o APL de vitivinicultura.

A experiência de Ensino Médio Integrado no IFSP de São Roque demonstra não apenas a influência do segundo setor na formulação da educação, tal como a teoria do capital humano ainda se mantém viva, trazendo consigo a percepção de que a educação pode se desenvolver como meio para alcançar o desenvolvimento econômico. Consequentemente, esta pode ser uma das faces para compreender a identidade e os interesses do "novo" Ensino Médio.

\section{REFERÊNCIAS}

ANTUNES, R. L. C. Os sentidos do trabalho: ensaio sobre a afirmação e a negação do trabalho. 3. ed. São Paulo: Boitempo, 2009.

AMATO NETO, J. Redes de cooperação produtiva e clusters regionais: oportunidades para pequenas empresas. São Paulo: Atlas: Fundação Vanzolini, 2008.

BRASIL. 2016a. Novo Ensino Médio: dúvidas. Ministério da Educação. Disponível em:<http://portal.mec.gov.br/component/conte nt/article?id=40361\#nem_01> Acesso em: 20set. 2017.

BRASIL. 2016b. Ministério da educação. Projeto político pedagógico curso de ensino médio integrado ao ensino técnico em produção alimentícia. IFSP. São Roque. Disponível em: http://www.ifsp.edu.br/index.php/37-sorocabacampus-avancado.html Acesso em: 18 de mar. 2016

CHESNAIS, François. A mundialização do capital. São Paulo: Xamã, 1996.

DARDOT, P.; LAVAL, C. A nova razão do mundo. São Paulo: Boitempo, 2016.

DUMÉNIL, G.; LÉVY, D. A crise do neoliberalismo. São Paulo: Boitempo, 2014.

FERRETI, C. J.; SILVA, M. R. Reforma do Ensino Médio no contexto da medida provisória $n^{\circ}$ 746/2016: Estado, currículo e disputas por hegemonia. Educação \& Sociedade, Campinas, v. 38, n. 139, p. 385-404, abr./jun. 2017. https://doi.org/10.1590/es0101-

\section{7}

FRIGOTTO, G. A produtividade da escola improdutiva: um (re) exame das relações entre educação e estrutura econômico-social capitalista. 9. ed. São Paulo: Cortez, 2010.

GARCIA, R. Economias externas e vantagens competitivas dos produtores em sistemas locais de produção: as visões de Marshall, Krugman e Porter. Ensaios FEE, Porto Alegre, v. 27, n. 2, p. 301-324, out. 2006.

GUIMARÃES, N. A. À procura de trabalho: instituições do mercado e redes. Belo Horizonte, MG: Argvmentvm, 2009.

HARVEY, D. Condição pós-moderna: uma pesquisa sobre as origens da mudança cultural. 22. ed. São Paulo: Loyola, 2012.

IBGE. 2017. Perfil sócio econômico municipal: São Roque. Disponível em:<http://cidades.ibge.gov.br/xtras/perfil.php? codmun $=355060>$ Acesso em: 20set. 2017

INEP. Censo Escolar da Educação Básica 2013: resumo técnico. - Brasília: O Instituto, 2014. Disponível em: $<$ http://download.inep.gov.br/educacao_basica/c enso_escolar/resumos_tecnicos/resumo_tecnico _censo_educacao_basica_2013.pdf > Acesso em: set. de 2016

KRAWCZYK, N. (Org.). Sociologia do ensino médio: crítica ao economicismo na política educacional. São Paulo: Cortez, 2014.

MOTTA, V. C.; FRIGOTTO, G. Por que a urgência da reforma do Ensino Médio? medida provisória no 746/2016 (lei no 13.415/2017). Educação \& Sociedade, Campinas, v. 38 , n. 139 , p.355-372, abr./jun. 2017. https://doi.org/10.1590/es0101$\underline{73302017176606}$

OBSERVATÓRIO NACIONAL DE APL. APL do Vinho em São Roque. Disponível em: $<$ http://portalapl.ibict.br/apls/index.html\#SP598-VinhoDeSaoRoque-info> Acesso em: 15 jan. 2015

OLIVEIRA, C. D. Arranjos produtivos no segundo setor na região de Sorocaba e as políticas públicas de ensino médio. Relatório de iniciação científica. Universidade de Sorocaba, 2015. 
PDI. Plano de Desenvolvimento Institucional dos Institutos Federais de Educação, Ciência e Tecnologia do Estado de São Paulo 2014-2018. Disponível em:

<http://www.ifsp.edu.br/index.php/outrasnoticias/52-reitoria/2263-comissao-publicaversao-final-do-pdi-2014-2018.html> Acesso em: 15 dez. 2014.

POCHMANN, M. Desenvolvimento e perspectivas novas para o Brasil. São Paulo: Cortez, 2010.

POCHMANN, M. Emprego na globalização. São Paulo: Boitempo, 2012.

RAMOS NETO, J. O. Como a reforma do Ensino Médio afeta a rede federal de Educação Tecnológica. Multi-Science Journal, Urutaí, v. 1, n 7. p. 09-11, set/nov. 2017

REDE PAULISTA DE ARRANJOS PRODUTIVOS LOCAIS. O programa estadual de APL. São Paulo, 2009. Disponível em: <http://www.desenvolvimento.gov.br/conferenci aapl/modulos/arquivos/Miltonlamanau kas.pdf>. Acesso em: abr. 2016.

SACOMANO NETO, M.; PAULILLO, L. Estruturas de governança em arranjos produtivos locais: um estudo comparativo nos arranjos calçadistas e sucroalcooleiros no estado de São Paulo. Revista Administração Pública, Rio de Janeiro, v. 46, n. 4, p. 1131-1155, jul./ago. 2012.

SANFELICE, J. L. História das instituições escolares. In: NASCIMENTO, M. I. M.; SANDANO, W.; LOMBARDI, J. C.; SAVIANI, D. (Org). Instituições Escolares no Brasil: conceito e reconstrução histórica. Campinas: Autores Associados, HISTEDBR; Sorocaba: Uniso; Ponta Grossa: UEPG; São Paulo: Cia das Letras, 2007. p. 75-94.

SÃO PAULO. Decreto № 54.654, de 7 de agosto de 2009. Institui o Programa Estadual de Fomento aos Arranjos Produtivos Locais, autoriza a celebração de convênios com municípios do Estado de São Paulo e entidades que especifica, visando à transferência de recursos financeiros para o incremento das cadeias produtivas, e dá providências correlatas. Assembleia Legislativa do Estado de São Paulo, 7 ago. 2009. Disponível em: http://www.al.sp.gov.br/repositorio/legislacao/d ecreto/2009/decreto-54654-07.08.2009.html

SEADE. Índices dos municípios paulistas. Disponível em: < http://www. http://www.imp.seade.gov.br/frontend/\#/perfil > Acesso em: 25 mar. 2015.

SINGER, A. A (falta de) base política para o ensaio desenvolvimentista. In: SINGER, A; LOUREIRO, I. (Orgs.). As contradições do lulismo: a que ponto chegamos? São Paulo: Boitempo, 2016. p. 21-54.

SPOSITO, M. P.; SOUZA, R. Desafios da reflexão sociológica para análise do ensino médio no Brasil. In: KRAWCZYK, N. Sociologia do ensino médio Crítica ao economicismo da política educacional. São Carlos/SP: Cortez, 2014. p. 3362.

Recebido para publicação em: 06/11/2017 Revisado em: 31/01/2018

Aceito em: 09/03/2018 